CLINICAL STUDY

\title{
Clinical, hormonal and magnetic resonance imaging (MRI) predictors of transsphenoidal surgery outcome in acromegaly
}

\author{
Aline Bourdelot ${ }^{1}$, Joel Coste ${ }^{2}$, Vincent Hazebroucq ${ }^{3}$, Stephan Gaillard ${ }^{4}$, Laure Cazabat ${ }^{1,5}$, Xavier Bertagna ${ }^{1,5}$ and $^{1}$ \\ Jérôme Bertherat ${ }^{1,5}$ \\ ${ }^{1}$ Endocrinology Department, ${ }^{2}$ Department of Biostatistics, ${ }^{3}$ Radiology Department, Hôpital Cochin, 75014, Paris, ${ }^{4}$ Department of Neurosurgery and \\ Hôpital Foch, 92000, Suresnes, ${ }^{5}$ Department of Endocrinology, Institut Cochin, INSERM U576, CNRS UMR 8104, IFR116, Université Paris V-René \\ Descartes, 75014, Paris, France
}

(Correspondence should be addressed to J Bertherat, Service des Maladies Endocriniennes et Métaboliques, Hôpital Cochin, 27 rue du Fg-St-Jacques, 75014, Paris, France; Email: jerome.bertherat@cch.ap-hop-paris.fr)

(V Hazebroucq is currently at Faculté de Médecine Cochin-Port-Royal, Université Paris V)

\begin{abstract}
Objective: Progress in the treatment of acromegaly with drugs is making it necessary to improve the prediction of the outcome of transsphenoidal surgery.

Design: We evaluated clinical, hormonal and radiologic predictors based on magnetic resonance imaging (MRI) of surgical outcome in patients with acromegaly.

Methods: This retrospective analysis included 125 consecutive patients investigated for acromegaly in a single endocrine unit since the use of MRI imaging began (1988). Eighty-three of these patients (50 women) underwent transsphenoidal surgery and were investigated before and after surgery in our department. A neuroradiologist unaware of the surgical outcome analyzed the results of pituitary gland MRI investigations.

Results: Surgical remission rates were $44 \%, 43 \%, 61 \%$ and $59 \%$ based on mean basal GH concentration under $2.5 \mu \mathrm{g} / \mathrm{l}$, GH/oral glucose tolerance test (OGTT) of $<1 \mu \mathrm{g} / \mathrm{l}$, GH/OGTT of $<2 \mu \mathrm{g} / \mathrm{l}$ or IGF-I concentration normal for age and sex respectively. In univariate logistic regression analysis with IGF-I concentration used as the criterion for cure, young age $(P<0.001)$, high IGF-I concentration before surgery $(P<0.01)$, high basal GH concentration before surgery $(P<0.02)$, and high nadir GH/OGTT before surgery $(P=0.03)$ were predictors of poor outcome. The following results in standardized MRI analysis were associated with a higher probability of not being cured: adenoma greater than $15 \mathrm{~mm}$ in diameter $(P<0.02)$, infrasellar extension $(P=0.04)$, suprasellar extension $(P<0.005)$ and invasive adenoma $(0.02)$ according to MRI staging. MRI analysis of the intracavernous extension showed that stages above B2 (possible sinus extension with sign of invasion of the space below the carotid artery) were associated with a lower probability of postoperative normal GH plasma levels $(P=0.01)$. In multivariate analysis, age, preoperative hormonal levels and adenoma size remained the major predictors of surgical outcome.

Conclusions: This report provides the first evidence that detailed MRI analysis of adenoma size, location and potential invasion, together with preoperative clinical and hormonal parameters, can be used for the prediction of hormonal outcome after transsphenoidal surgery for acromegaly.
\end{abstract}

European Journal of Endocrinology 150 763-771

\section{Introduction}

For more than 30 years, transsphenoidal neurosurgery has been considered the first-choice treatment for acromegaly caused by pituitary growth hormone (GH)-secreting adenoma (1-4). However, if strict biochemical criteria are used (5), the postsurgical remission rate is less than $60 \%(6-8)$. Epidemiologic studies have shown that the high rates of morbidity and mortality associated with acromegaly can be greatly reduced by controlling $\mathrm{GH}$ levels (9-13). Adjuvant therapy, by radiotherapy and/or drug treatment, is often needed after surgery to achieve such control (14). The indications for radiotherapy are limited due to the time lag before this treatment has an effect and the high risk of inducing hypopituitarism $(15,16)$. Drug treatments, initially with dopamine agonists, and with somatostatin analogs have been developed. Somatostatin analogs are effective in $50-70 \%(17-$ 19) of cases. The GH receptor antagonist pegvisomant has proved highly effective (20). Recently, somatostatin analogs $(21-25)$ have been proposed as first-choice treatments for patients with no unequivocal indications for surgery (compression of the optic chiasma, for 
example), and might be discussed as well in the future for pegvisomant (26). These important pharmacologic advances have led to considerable debate about whether drug treatments (mainly with somatostatin analogs) should be used as a first-line treatment. Drug treatment before surgery was initially suggested for patients with severe cardiopulmonary complications of acromegaly. More recently, first-line drug treatment was also suggested for patients with a low probability of surgical cure (invasive macroadenoma).

However, surgery remains the only way to cure acromegaly, with the restoration of a normal $\mathrm{GH}$ secretion profile following complete, selective removal of the adenoma. This highlights the need for predictors of surgical outcome. Some criteria, such as the differences between macro- and microadenomas $(27,28)$, preoperative mean basal GH concentration (29) and the experience of the surgeon $(30,31)$, have already been identified.

Magnetic resonance imaging (MRI) is now the reference standard for the investigation of pituitary adenomas, providing invaluable information about tumor size and extension $(32,33)$. It is also useful for the assessment of intracavernous extension (ICE), which hampers the complete surgical removal of pituitary adenoma. However, the use of MRI to predict ICE has its limits $(34,35)$, and no reliable radiologic predictor has yet been identified in patients with acromegaly (36). The possibility of predicting surgical outcome on the basis of preoperative pituitary MRI has not been fully investigated in acromegaly.

We tried to identify clinical, hormonal and pituitary MRI predictors of surgical outcome by retrospectively reviewing the medical charts of 83 operated patients out of 125 consecutive newly diagnosed patients with acromegaly investigated in our department since the advent of pituitary MRI in 1988.

\section{Patients and methods}

\section{Patients}

We identified every newly diagnosed patient with acromegaly seen at the Department of Endocrinology of Cochin Hospital (Paris, France) since 1988. Of the 125 consecutive patients identified, 83 patients underwent surgery, had pre- and postoperative biochemical assessment in our department and were therefore selected for this analysis that was performed according to the rules of the Institutional Review Board of Cochin Hospital.

\section{Endocrine investigation}

For basal GH level measurements, we report the mean value of samples obtained during the day. For GH measurements during oral glucose tolerance test (OGTT), $75 \mathrm{~g}$ glucose were administered orally, and
GH assays were performed on plasma samples collected after 0 and $60 \mathrm{~min}$ of the OGTT. GH was assayed by RIA with the CIS-Bio International Kit (Gif-surYvette, France) between 1988 and 1990, and by immunoradiometric assay (IRMA) with the CIS-Bio International Kit (lower detection threshold, $0.04 \mu \mathrm{g} / \mathrm{l})$ thereafter. Correlation analysis of the results obtained in RIA and IRMA GH assays showed that the GH level obtained was $10 \%$ higher if the sample was assayed with RIA than if assayed by IRMA.

Plasma insulin-like growth factor-I (IGF-I) concentration was determined by RIA, as previously reported (15). IGF-I was separated from its binding proteins with the INCSTAR Kit (Stillwater, MN, USA) with Sep-Pak column extraction or gel filtration before 1993 (15) and acid/ethanol extraction with the Nichols Institute Diagnostics Kit (San Juan Capistrano, CA, USA) thereafter. For plasma IGF-I concentration, results are expressed as a percentage of the upper limit of the normal age- and sex-adjusted range (\% upper limit of normal (ULN)).

Acromegaly was diagnosed on the basis of the presence of relevant clinical features, and diagnosis was confirmed by the demonstration of a mean GH concentration over $5 \mu \mathrm{g} / \mathrm{l}$ and/or plasma IGF-I concentration above the normal range for age and sex and/or nadir GH/OGTT of $>1 \mu \mathrm{g} / \mathrm{l}$. The mean time between preoperative biochemical assessment and surgery was 3 months (1 day-20 months). The mean time between surgery and postoperative biochemical assessment was 5 months ( 1 month-1 year).

\section{Surgical procedure and analysis}

Transsphenoidal surgery was performed via a sublabial or transnasal approach, with the aid of an image intensifier; 74 patients were operated at the Department of Neurosurgery of Foch Hospital (Suresnes, France).

After tumor removal, routine histopathologic analysis was performed to establish the pattern of reticulin staining and routine immunostaining for pituitary hormones. Immunostaining for $\mathrm{GH}$ was positive in all cases.

Fifty-seven homogeneous surgical records for procedures carried out by the same surgeon (Dr P Derome) were subjected to standardized retrospective analysis by the same neurosurgeon, blind to the endocrine outcome after surgery: tumor size, suprasellar extension (SSE), infrasellar extension (ISE), intracavernous extension, peri- and postoperative complications (hemorrhage, cerebrospinal fluid (CSF) leak, hyponatremia by syndrome of inappropriate antidiuretic hormone secretion (SIADH), diabetes insipidus, sinusitis and meningitis) and tumor removal (complete, incomplete or uncertain). 


\section{Radiologic analysis}

All patients underwent preoperative imaging of the pituitary fossa; $12 / 83(14.5 \%)$ had CT scans and $71 / 83(85.5 \%)$ had MRI in the sagittal and coronal planes, with and without gadolinium enhancement.

Sixty-two of the $71(87 \%)$ MRI images were available at the time of the study and were used for standardized analysis by the same neuroradiologist, who was unaware of the surgical outcome. Tumors were classified on the basis of size, SSE, ISE or ICE.

Tumor size Tumor size was defined as the largest tumor diameter measured and was subdivided a priori before analyzing the MRI into seven grades: $\mathrm{a}=0 \mathrm{~mm}$ (adenoma not detected by MRI), $\mathrm{b}<3 \mathrm{~mm}$, $\mathrm{c}=3-7 \mathrm{~mm}, \quad \mathrm{~d}=7.1-10 \mathrm{~mm}, \quad \mathrm{e}=10.1-15 \mathrm{~mm}$, $\mathrm{f}=15.1-20 \mathrm{~mm}$ and $\mathrm{g}>20 \mathrm{~mm}$.

Suprasellar extension (SSE) SSE was subdivided into four stages: $\mathrm{A}=$ no extension, $\mathrm{B}=$ simple sellar diaphragm bulge, $\mathrm{C}=$ extension not reaching optic chiasma and $\mathrm{D}=$ massive extension above optic chiasma.

Infrasellar extension (ISE) ISE was subdivided into two stages: $\mathrm{A}=$ no extension and $\mathrm{B}=$ suspected extension into the sphenoidal sinus (adenoma tissue detected by MRI in the anatomic space occupied by the sphenoidal sinus).

Intracavernous extension (ICE) ICE (Fig. 1) was subdivided into seven stages: $\mathrm{A}=$ no extension; $\mathrm{B} 1=$ possible sinus extension with no sign of invasion of the space below the carotid artery; B2 = possible extension with signs of invasion of the space below the carotid artery; $\mathrm{C} 1=$ probable extension with no sign of invasion of the space below the carotid artery; $\mathrm{C} 2=$ probable extension with signs of invasion of the space below the carotid artery; $\mathrm{D}=$ massive extension; and $\mathrm{E}=$ extension into the temporal fossa.

For statistical analysis, classification on the basis of SSE and ICE results was also performed: an adenoma with an ICE of stage A to B2 that did not reach the

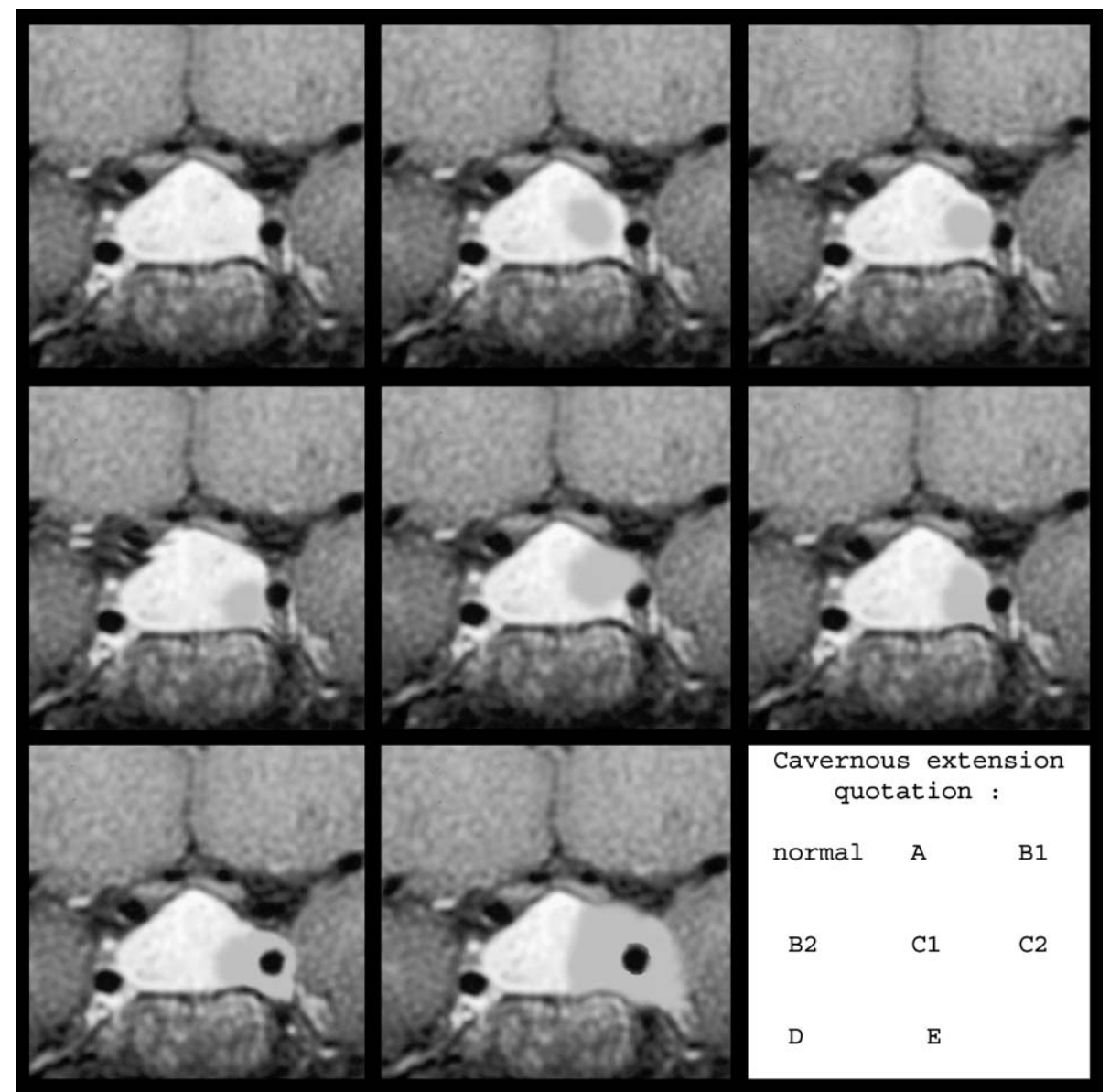

Figure 1 Neuroradiologic staging of intracavernous extension (ICE). Theoretical examples corresponding to each of the seven stages (A, B1, B2, C1, C2, D and E), as described in the methods section, are shown. The figure was drawn from a pituitary MRI scan to illustrate the various stages of tumor extension. 
optic chiasma was considered noninvasive; in all other cases, it was classified as an invasive adenoma.

\section{Statistical analysis}

Clinical, biologic and radiologic data were recorded in a Microsoft Access 98 computerized database. For radiologic analysis of pituitary MRI, we defined a new size-independent class for invasive adenomas: adenomas with SSE above the optic chiasma and ICE above B2. Criteria for cure of acromegaly were established from recently published data $(22,24,28,30,37)$ : mean GH concentration of $<2.5 \mu \mathrm{g} /$, nadir GH/OGTT of $<1 \mu \mathrm{g} / \mathrm{l}$ and normal plasma IGF-I concentration for age and sex. Postoperative assessments were made between 30 and 365 days after surgery.

Quantitative clinical and biologic variables were described with means \pm S.D. Analyses included Student's t-test, chi-square test, and ANOVA, which were all carried out with the SAS package (SAS Institute Inc., Cary, NC, USA). Logistic regression analysis was used to analyze predictors of outcome. Results were considered statistically significant if the two-tailed $P$ value was $<0.05$. First, we explored the predictive value of each preoperative radiologic and biologic variable in a logistic model including age and duration of acromegaly. Odds ratio (OR) and 95\% confidence intervals (CI) were calculated for this predictive value. We also tested overall surgical outcome, with OR adjusted for age and duration of acromegaly. We added all variables significant in the univariate analysis to a multivariate model, including age, duration of acromegaly and preoperative IGF-I concentration normalized for age and sex, and a second model, including age, duration of acromegaly and preoperative GH concentration.

\section{Results}

\section{Patients}

The mean age of the 83 patients was $44.3 \pm 12.9$ years (mean \pm s.D.) at the time of diagnosis of acromegaly, with a female/male ratio of 1.5/1 (50 women and 33 men). The mean estimated duration of acromegaly before diagnosis was $6.0 \pm 5.1$ years. The mean time between diagnosis and surgery was 5.6 \pm 12.2 months (Table 1).

\section{Hormonal results before and after surgery}

Before surgery (Table 1), mean basal GH concentration was $55.6 \pm 103.8 \mu \mathrm{g} / \mathrm{l}$. Mean nadir GH/OGTT was $51.3 \pm 134.9 \mu \mathrm{g} / \mathrm{l}$. Mean IGF-I level was $188.5 \pm 109.9 \%$ ULN.

After surgery (Table 2), mean basal GH concentration was $47.5 \pm 244.8 \mu \mathrm{g} / \mathrm{l}$. Mean nadir GH/OGTT was $9.3 \pm 28.6 \mu \mathrm{g} / \mathrm{l}$. Mean IGF-I level was $107.5 \pm 71.2 \%$. Thirteen of the 83 patients had postoperative investigations in our department in under

Table 1 Clinical, biologic and radiologic analysis before surgery.

\begin{tabular}{|c|c|c|c|c|}
\hline & Number & Mean \pm S.D. & Minimum & Maximum \\
\hline Duration of acromegaly before diagnosis (years) & 83 & $6.0 \pm 5.1$ & 1 & 27.0 \\
\hline Delay between diagnosis and surgery (years) & 83 & $0.47 \pm 1.03$ & 0 & 9.0 \\
\hline Age (years) & 83 & $44.35 \pm 12.95$ & 17.80 & 78.33 \\
\hline Basal GH concentration ( $\mu \mathrm{g} / \mathrm{l})$ & 83 & $55.65 \pm 103.86$ & 2.20 & 698.00 \\
\hline Nadir GH/OGGT $(\mu \mathrm{g} / \mathrm{l})$ & 69 & $51.37 \pm 134.94$ & 0.33 & 1070.0 \\
\hline IGF-I (\%) & 74 & $188.52 \pm 109.93$ & 25.27 & 800.0 \\
\hline Size of adenoma $(\mathrm{mm})$ & 83 & $16.0 \pm 8.49$ & 4.0 & 50.0 \\
\hline MRI analysis & & Number $(n=62)$ & & Percent (\%) \\
\hline \multicolumn{5}{|l|}{ Adenoma size (mm) } \\
\hline$\bullet<3(b)$ & & 0 & & 0 \\
\hline$\cdot 3-7$ (c) & & 9 & & 15 \\
\hline$\bullet 7.1-10(d)$ & & 7 & & 11 \\
\hline$\bullet 10.1-15(\mathrm{e})$ & & 16 & & 26 \\
\hline$\bullet 15.1-20(\mathrm{f})$ & & 17 & & 27 \\
\hline$\bullet>20(\mathrm{~g})$ & & 13 & & 21 \\
\hline Suprasellar extension (SSE) & & 51 & & 82 \\
\hline - No extension $(A)$ & & 0 & & 0 \\
\hline -Sellar diaphragm bulge (B) & & 22 & & 35 \\
\hline$\bullet<$ Optic chiasma (C) & & 18 & & 29 \\
\hline •> Optic chiasma (D) & & 11 & & 18 \\
\hline Infrasellar extension (ISE) & & 25 & & 41 \\
\hline Intracavernous extension (ICE) & & 48 & & 77 \\
\hline -A & & 14 & & 22 \\
\hline$\bullet B 1$ & & 12 & & 19 \\
\hline -B2 & & 13 & & 21 \\
\hline$\cdot \mathrm{C} 1+\mathrm{C} 2$ & & 14 & & 23 \\
\hline$\cdot D+E$ & & 9 & & 15 \\
\hline
\end{tabular}


Table 2 Biologic analysis after surgery.

\begin{tabular}{lccc}
\hline & Number & Mean \pm s.D. & Range \\
\hline Delay after surgery (days) & 70 & $148.65 \pm 78$ & $32-358$ \\
Basal GH $(\mu \mathrm{g} / \mathrm{l})$ & 70 & $47.56 \pm 244.84$ & $0.125-2000$ \\
GH/OGGT nadir $(\mu \mathrm{g} / \mathrm{l})$ & 51 & $9.37 \pm 28.64$ & $0.1-194$ \\
IGF-I $\%$ ) & 68 & $107.59 \pm 71.27$ & $22-383$ \\
Criteria for cure & Patients analysed & & Patients cured \\
Basal GH concertration $<2.5 \mu \mathrm{g} / \mathrm{l}$ & 70 & $31(44 \%)$ \\
$\bullet$ GH/OGGT $<1 \mu \mathrm{g} / \mathrm{l}$ & 51 & $22(43 \%)$ \\
$\bullet$ IGF-I nomalized for age and sex & 68 & $40(59 \%)$ \\
Total & 189 & $93(49 \%)$ \\
\hline
\end{tabular}

30 days or more than 365 days after surgery. Their results were excluded from the analysis.

Surgical remission rate was $44.3 \%(31 / 70), 43.1 \%$ $(22 / 51), 61 \%(31 / 51)$ and $58.8 \%(40 / 68)$ for the criteria GH concentration of $<2.5 \mu \mathrm{g} / \mathrm{l}$, GH/OGTT of $<1 \mu \mathrm{g} / \mathrm{l}$, GH/OGTT of $<2 \mu \mathrm{g} / \mathrm{l}$ and IGF-I normal for age and sex respectively. The combined surgical cure rate for all tumors, regardless of tumor size, was $49 \%$ $(93 / 189)$ for the three most stringent criteria (Table 2).

\section{Surgical analysis}

Minor perioperative complications, such as CSF leaks and hemorrhage, were observed in $3.4 \%$ and $2.4 \%$ of patients respectively. No modification of the surgical technique was required and no late complications appeared. There were no instances of postoperative CSF rhinorrhea, meningitis or definitive diabetes insipidus. The transient postoperative complications of diabetes insipidus and hyponatremia were observed in seven patients $(8.4 \%)$ each. One patient died of postoperative pulmonary embolism, despite low-molecular-weight heparin prophylaxis.

From the analysis of neurosurgical records (and not from the MRI standardized analysis reported below), SSE was found in $28 / 57$ patients (49.1\%), ISE in $6 / 57$ patients $(10.5 \%)$ and ICE in $9 / 57$ patients (15.8\%). Tumor removal was considered incomplete in $8 / 57$ patients $(14.0 \%)$, complete in $40 / 57$ patients $(70.2 \%)$ and uncertain in nine patients (15.8\%). Finally, neurosurgeons considered tumor removal successful according to the operative findings in only $70 \%$ of cases $(40 / 57)$.

\section{MRI analysis}

Microadenomas were found in 16 patients $(25.8 \%)$ and macroadenomas in 46 patients $(74.2 \%)$. Tumor size analysis (Table 1) showed that there were no adenomas in groups a or b (diameter of $<3 \mathrm{~mm}$ ), nine in group $\mathrm{c}$ (14.5\%, diameter: $3-7 \mathrm{~mm})$, seven in group d $(11.3 \%$, diameter $7.1-10 \mathrm{~mm}), 16$ in group e $(25.8 \%$, diameter $10.1-15 \mathrm{~mm}), 17$ in group $\mathrm{f}(27.4 \%$, diameter $15.1-$ $20 \mathrm{~mm})$ and 13 in group $\mathrm{g}(20.9 \%$, diameter above $20 \mathrm{~mm})$. SSE analysis found 11 adenomas in group A
$(17.7 \%), 22$ in group B (35.4\%), 18 in group C $(29 \%)$ and 11 in group D $(17.7 \%)$. ISE was found in 25 adenomas $(41 \%)$. ICE analysis found 14 adenomas in group A $(22.5 \%), 12$ in group B1 (19.3\%), 13 in group B2 (20.9\%), 14 in groups C1 and C2 $(22.5 \%)$ and nine in groups D and E (14.5\%). Finally, the neuroradiologist suspected ICE in more than $77 \%$ of the cases.

\section{Factors predictive of surgical outcome}

Univariate analysis, with IGF-I concentration as the criterion for cure (Table 3, Fig. 2), revealed that younger age $(P=0.001)$, tumor diameter greater than $15 \mathrm{~mm}$ $(P=0.013)$, SSE above the optic chiasma $(P=0.005)$, ISE $(P=0.04)$, invasive adenomas (as defined in the Patients and methods section, $P=0.02)$, preoperative higher basal GH level $(P=0.02)$, higher nadir

Table 3 Univariate logistic regression analysis with IGF-I as criterion for cure.

\begin{tabular}{|c|c|c|}
\hline & OR $95 \% \mathrm{Cl}$ & $\boldsymbol{P}$ \\
\hline Age & $0.91(0.86-0.96)$ & 0.001 \\
\hline \multicolumn{3}{|l|}{ Sex } \\
\hline -Male & 1 & \\
\hline$\bullet$ Female & $1.24(0.39-3.94)$ & 0.56 \\
\hline \multicolumn{3}{|l|}{ Adenoma size (MRI) } \\
\hline$\bullet<15 \mathrm{~mm}$ & 1 & \\
\hline - > $>15 \mathrm{~mm}$ & $7.04(1.49-33.2)$ & 0.013 \\
\hline \multicolumn{3}{|l|}{ SSE (MRI) } \\
\hline • < Optic chiasma & 1 & \\
\hline - > Optic chiasma & $12(2.14-67.6)$ & 0.005 \\
\hline \multicolumn{3}{|l|}{ ISE (MRI) } \\
\hline • No (B) & 1 & \\
\hline - Yes (A) & $5(1.11-22.7)$ & 0.04 \\
\hline \multicolumn{3}{|l|}{ ICE (MRI) } \\
\hline$\bullet A+B 1+B 2$ & 1 & \\
\hline$\bullet \mathrm{C} 1+\mathrm{C} 2+\mathrm{D}+\mathrm{E}$ & $3.96(0.91-17.16)$ & 0.06 \\
\hline \multicolumn{3}{|l|}{ Invasive adenoma (MRI) } \\
\hline $\begin{array}{l}\bullet \mathrm{A}+\mathrm{B} 1+\mathrm{B} 2 \text { and } \\
<\text { optic chiasma }\end{array}$ & 1 & \\
\hline $\begin{array}{l}\bullet \mathrm{C} 1+\mathrm{C} 2+\mathrm{D}+\mathrm{E} \\
\text { or }>\text { optic chiasma }\end{array}$ & $7.2(1.32-39)$ & 0.02 \\
\hline Basal GH concentration & $1.02(1.00-1.03)$ & 0.02 \\
\hline Nadir GH/OGGT & $1.02(1.00-1.40)$ & 0.03 \\
\hline IGF-I normalized for age and sex & $1.02(1.00-1.02)$ & 0.01 \\
\hline
\end{tabular}

Significant numbers (i.e. $<0.05$ ) are in bold. 


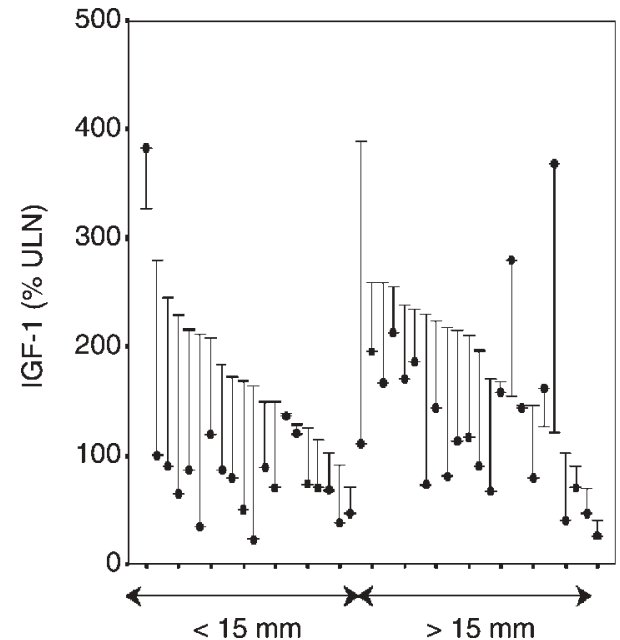

A

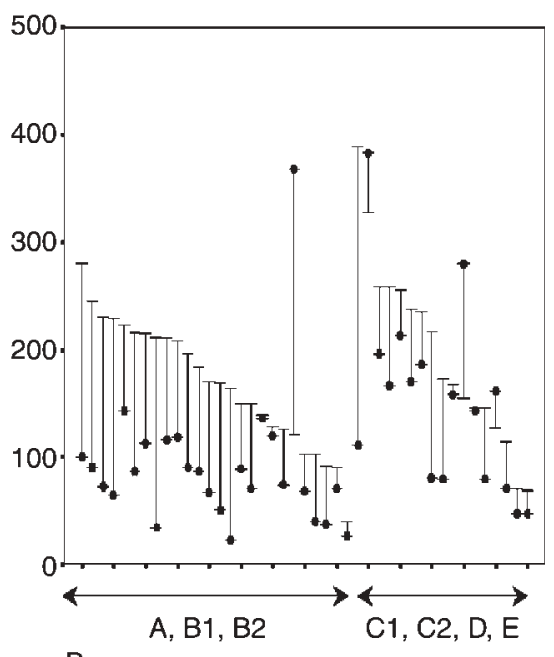

B

Figure 2 Pre- and postoperative plasma IGF-I levels according to adenoma size and ICE, as determined by MRI analysis. IGF-I level is expressed as a percentage of the normal value adjusted for age and sex. For each patient $(n=43)$, the preoperative (line) and postoperative (closed square) values of IGF-I level are shown. (A) Classification of the patients into two groups according to adenoma size, as determined by standardized MRI analysis. (B) Classification of the patients into two groups according to cavernous sinus extension, as determined by standardized MRI analysis.

GH/OGTT $(P=0.03)$ and higher IGF-I level $(P=0.01)$ were predictive of disease persistence after transsphenoidal surgery. ICE was not identified as predictive, but $P$ was close to the significance threshold (0.06). Multivariate analysis showed that preoperative IGF-I level and adenoma size were significantly associated with normal postoperative plasma IGF-I levels (OR: 0.986, CI: 0.972-1.00, for IGF-I; OR: 0.143, CI: 0.0250.819 , for adenoma diameter greater than $15 \mathrm{~mm}$ ). Univariate analysis, with $\mathrm{GH}$ concentration of $<2.5 \mu \mathrm{g} / \mathrm{l}$ as the criterion for cure (Table 4, Fig. 3), revealed ICE above

Table 4 Univariate logistic regression analysis with basal GH as criterion for cure.

\begin{tabular}{|c|c|c|}
\hline Variable & OR $95 \% \mathrm{Cl}$ & $P$ \\
\hline Age & $0.94(0.89-0.99)$ & 0.03 \\
\hline \multicolumn{3}{|l|}{ Sex } \\
\hline $\begin{array}{l}\text { - Male } \\
\text { - Female }\end{array}$ & 5 (1) & 0.008 \\
\hline \multicolumn{3}{|l|}{ Adenoma size (MRI) } \\
\hline $\begin{array}{l}\bullet<15 \mathrm{~mm} \\
\bullet>15 \mathrm{~mm}\end{array}$ & $\frac{1}{526(141-1956)}$ & 001 \\
\hline \multicolumn{3}{|l|}{ SSE (MRI) } \\
\hline $\begin{array}{l}\text { - }<\text { Optic chiasma } \\
->\text { Optic chiasma }\end{array}$ & $2.84(0.82-9.82)$ & 0.1 \\
\hline ISE (MRI) & & \\
\hline $\begin{array}{l}\text { - No (B) } \\
\text { - Yes (A) }\end{array}$ & $2 \begin{array}{c}1 \\
2(0.56-7.04)\end{array}$ & 0.28 \\
\hline \multicolumn{3}{|l|}{ ICE (MRI) } \\
\hline $\begin{array}{c}\bullet \mathrm{A}+\mathrm{B} 1+\mathrm{B} 2 \\
\bullet \mathrm{C} 1+\mathrm{C} 2+\mathrm{D}+\mathrm{E} \\
\text { Invasive adenoma(MRI) }\end{array}$ & $\begin{array}{c}1 \\
5.5(1.43-21.05)\end{array}$ & 0.01 \\
\hline $\begin{array}{l}\cdot \mathrm{A}+\mathrm{B} 1+\mathrm{B} 2 \\
\text { and }<\text { optic chiasma }\end{array}$ & 1 & \\
\hline $\begin{array}{l}\cdot \mathrm{C} 1+\mathrm{C} 2+\mathrm{D}+\mathrm{E} \\
\quad \text { or }>\text { optic chiasma }\end{array}$ & $3.21(0.86-12.06)$ & 0.08 \\
\hline
\end{tabular}

Significant numbers (i.e. $<0.05$ ) are in bold.
B2 $(P=0.01)$ to be predictive of disease persistence after surgery. With GH concentration of $<2.5 \mu \mathrm{g} / \mathrm{l}$ as the criterion for cure, younger age $(P=0.03)$, tumor diameter greater than $15 \mathrm{~mm}(P=0.01)$, and female sex $(P=0.008)$ were also found to be associated with the persistence of $\mathrm{GH}$ hypersecretion after surgery (Table 4). In multivariate analysis, age, sex and adenoma size, as determined by MRI, were found to be close to the significance threshold, confirming the results obtained for IGF-I levels.

\section{Discussion}

This is the first study to analyze the correlation of a systematic, blind, standardized pituitary MRI analysis with the outcome of surgery for acromegaly. All the patients were newly diagnosed and had been followed in a single endocrine unit since the pituitary MRI entered into routine use (1988). Surgery was routinely performed as a first-line treatment in all patients. There was therefore no bias in patient selection. Indeed, during this period, only 22 of 125 patients did not undergo surgery. The characteristics of the adenoma were among the reasons for which surgery was not carried out in only eight of these cases, pituitary MRI showing the adenoma to be enclosed in the cavernous sinus. The preoperative parameters of our patients, such as age and sex distribution, mean duration of acromegaly before diagnosis, and tumor classification (micro/macroadenoma) were similar to those reported in previous studies $(6,8,12,28-30,38)$. The surgical cure rate for all tumors, regardless of tumor size (49\%), was similar to the mean of previously reported rates, which vary between $40 \%(12,27-29)$ and $60 \%(6,8,14,30)$. 

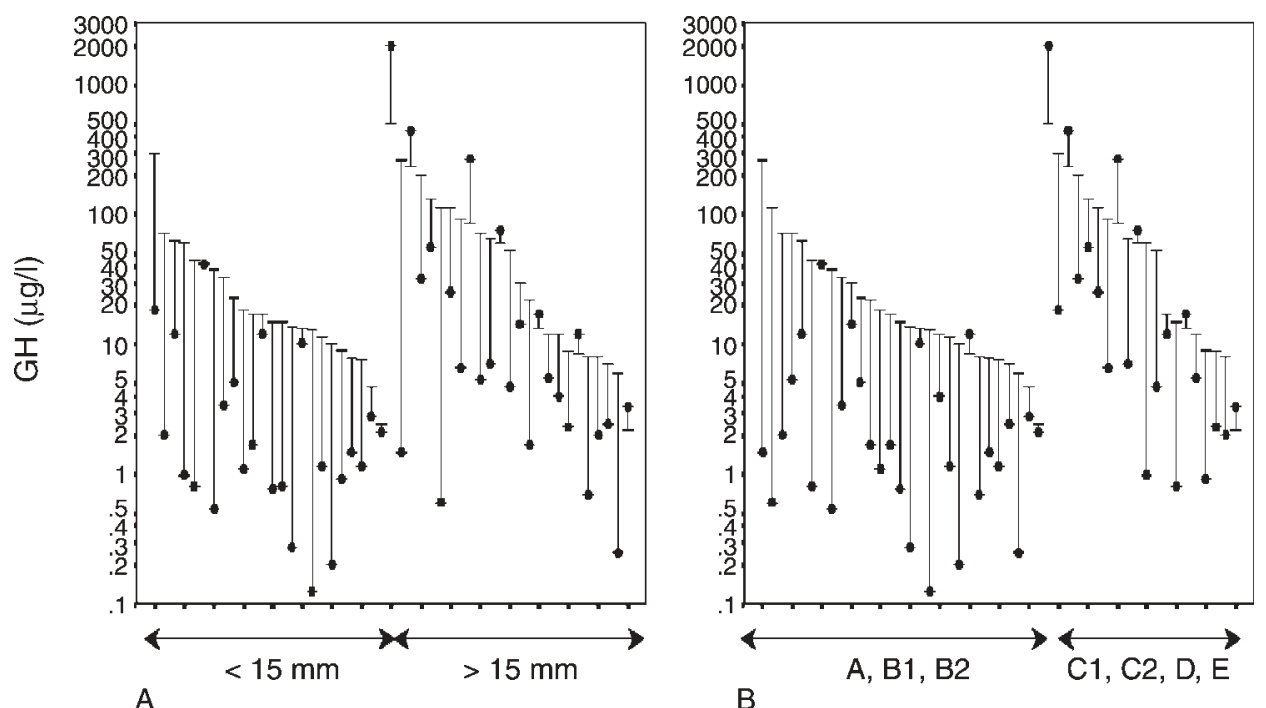

Figure 3 Pre- and postoperative plasma GH concentrations according to adenoma size and ICE, as determined by MRI analysis. For each patient $(n=49)$, the preoperative (line) and postoperative (closed square) values of mean basal GH concentration ( $\mu \mathrm{g} / \mathrm{l})$ are shown. (A) Classification of the patients into two groups according to adenoma size, as determined by standardized MRI analysis. (B) Classification of the patients into two groups according to cavernous sinus extension, as determined by standardized MRI analysis.

The current consensus criteria for cure of acromegaly (5) are basal GH concentration of $<2.5 \mu \mathrm{g} / \mathrm{l}$, nadir GH/OGTT of $<1 \mu \mathrm{g} / \mathrm{l}$ and normalization of IGFI values for age and sex. These criteria are more stringent than those used in most previous studies (38-40). However, it is known that a single parameter has its limits. Results for basal GH concentration are difficult to analyze because of pulsatility, fluctuations over time and sleep, and paradoxical responses. Levels of circulating IGF-I, which is primarily produced by the liver in response to $\mathrm{GH}$, vary to a much lesser extent and have been used as a criterion for cure since 1990 (41). Several studies have reported a strong correlation between these three criteria $(12,37,41)$, but others have reported discrepancies between IGF-I and basal GH $(28,42)$ results. Kaltsas et al. reported a good general correlation between GH and IGF-I but with many discrepancies between mean GH and IGF-I levels in individual patients (29). In our study, basal GH concentration of $<2.5 \mu \mathrm{g} / \mathrm{l}$ and nadir GH/OGTT of $<1 \mu \mathrm{g} / \mathrm{l}$ were well correlated with surgical remission rates of $44 \%$ and $43 \%$ respectively. IGF-I concentration normalized for age and sex seems to be more strongly correlated with nadir GH/OGTT of $<2 \mu \mathrm{g} / \mathrm{l}$, with surgical remission rates of $59 \%$ and $61 \%$ respectively. Technical pitfalls of IGF-I assays are well known in clinical practice, and IGF-I is also regulated by factors such as nutritional status, hepatic metabolism, protease activities, IGF-binding proteins (IGFBPs) and steroid hormones. Thus, IGF-I secretion does not exclusively reflect GH secretion. In all cases, false-positive and false-negative patients are identified for each criterion. According to Kreutzer et al. (7), any individual criterion for remission is not absolute. It would probably be better to define the remission of acromegaly in terms of two of these three criteria. However, the results obtained in this study were similar for each of the three criteria.

In this study, individual parameters such as being young and female were found to be associated with a lack of normalization of plasma GH level after surgery in univariate logistic regression analysis, as reported in previous studies $(6,12,14)$. The same applies to preoperative higher basal GH $(6,8,27,28,30,31,39,40)$ and preoperative higher IGF-I (39) levels. However, this study shows for the first time that high preoperative nadir GH/OGTT is also predictive of a poor outcome. It is difficult to identify threshold values for preoperative biochemical assessment that will predict postoperative results. Nevertheless, preoperative mean basal GH concentration $(117 \pm 159$ vs $25 \pm 41 \mu \mathrm{g} / \mathrm{l})$, mean nadir GH/OGTT (113 \pm 227 vs $22 \pm 29 \mu \mathrm{g} / \mathrm{l})$ and mean IGF-I level $(242 \pm 153 \%$ vs $145 \pm 57 \%)$ were significantly higher in uncured than in cured patients. In a study by Abosch et al. (12), 59\% of patients cured after surgery had preoperative basal GH levels of $<30 \mu \mathrm{g} / \mathrm{l}$, whereas $69 \%$ of uncured patients had basal GH levels of $>30 \mu \mathrm{g} / \mathrm{l}$. Ahmed et al. (30) found that patients with a preoperative basal $\mathrm{GH}$ concentration of $<20 \mathrm{mIU} / \mathrm{l}$ had a significantly higher cure rate than patients with preoperative basal $\mathrm{GH}$ concentrations of $>50 \mathrm{mIU} / \mathrm{l}$.

Standardized analysis of preoperative pituitary MRI scans by a radiologist blind to surgical outcome resulted in the identification of radiologic predictors of surgery outcome. One of the major predictors identified was tumor size. We found that the probability of cure was much lower for tumors with diameters greater than $15 \mathrm{~mm}$. In previous studies, tumor size was classified according to surgical and/or radiologic analysis, and in most studies only two groups were defined 
(micro- and macroadenomas), with an arbitrary cutoff point for diameter of $10 \mathrm{~mm}$. By this classification, based on nonstandardized analysis in most cases, the reported cure rate of macroadenomas was lower (below 50\%) than that of microadenomas (8, 14, 27, $28,30)$. This study involved a more precise analysis of the correlation between adenoma size and surgical outcome. We found that the probability of cure remained high for macroadenomas with diameters of 10-15 mm. By contrast, adenomas with diameters greater than $15 \mathrm{~mm}$ presented a relative risk of not being cured seven times higher than that for adenomas with a diameter of less than $15 \mathrm{~mm}$. SSE above the optic chiasma and ISE, as assessed by pituitary MRI in this study, were also associated with a lower rate of cure after surgery. Similar results have been based on surgical or radiologic analysis $(8,12,39,40)$.

ICE is one of the main problems facing the neurosurgeon attempting the complete removal of a pituitary adenoma. However, analysis of ICE is very difficult. Several MRI predictors of ICE have been proposed in neuroradiologic studies. Total enclosure of the intracavernous internal carotid artery (ICA) clearly proves the presence of ICE (34). The cavernous sinus may also be invaded when the lateral tangent of the supra- and the intracavernous ICA is crossed by the tumor, or if the percentage of ICA enclosure exceeds $25 \%$. According to Knosp et al. (35), ICE is surgically proven if the tumor expands between the intercarotid line and the lateral tangent line. This space corresponds to the B2 stage defined in this study. Of the 62 patients for which MRI results were available for standardized analysis, $23(37 \%)$ could therefore be considered to have an adenoma with clear invasion of the cavernous sinus (that is, stages $C$ to $E$ ), whereas the others had no ICE (stage A, $n=14 \%$ ) or could be considered as potentially having ICE (stages B1 and B2, $n=25 \%$ ). This study shows for the first time that standardized and precise staging of ICE is useful for the prediction of surgical outcome. ICE staging showing probable invasion with or without invasion of the space below the carotid artery (stages $\mathrm{C} 1$ and $\mathrm{C} 2$ ) or a massive extension (stages D and E) presents a relative risk of 5.5 of plasma GH concentrations not falling to optimal levels after surgery. The same staging associated with SSE to the optic chiasma presents a relative risk of 7.2 of persistent high IGF-I levels after surgery. This study also shows that the surgical classification of ICE is difficult. Indeed, the results of standardized analysis of data for transsphenoidal surgery were similar to the results of MRI analysis for massive ICE (15.8\% vs $14.5 \%$ ) and similar to those of previous studies $(34,35)$. However, overall, for invasive adenomas, ICE, as determined by surgical analysis, was probably underestimated, because the cure rate $(49 \%)$ was below the estimated rate of successful removal by the surgeon $(69 \%)$.

In summary, the probability of neurosurgery curing acromegaly as a first-line treatment is lower in young female patients and in patients with very high pretreatment GH and IGF-I levels. Preoperative MRI is very useful for the prediction of surgical results, as cure is much less likely in patients harboring tumors greater than $15 \mathrm{~mm}$ in diameter, with SSE above the optic chiasma and ISE, and with ICE classified above stage B2 according to our staging procedure. For these patients, adjuvant therapy is more likely to be required after surgery. This raises the question of whether an alternative first-line therapy should be considered if there is no neurologic consequence of tumor development and no risk of tumor in the short term. However, before we use such criteria to exclude surgery as a firstline treatment in patients presenting a very low probability of cure, further studies are required to assess whether the combination of surgery and drug treatment offers any advantage over drug treatment alone in such patients.

\section{Acknowledgements}

We thank the neurosurgeon Dr P Derome, the medical and paramedical staff of our endocrine department who cared for the patients, and Drs Y Fulla and M A Dugue for hormonal assays.

\section{References}

1 Laws ER Jr \& Thapar K. Pituitary surgery. Endocrinology and Metabolism Clinics of North America 199928 119-131.

2 Wilson CB. Surgical management of pituitary tumors. Journal of Clinical Endocrinology and Metabolism 199782 2381-2385.

3 Melmed S, Jackson I, Kleinberg D \& Klibanski A. Current treatment guidelines for acromegaly. Journal of Clinical Endocrinology and Metabolism $1998 \mathbf{8 3} 2646-2652$.

4 Hardy J. Transsphenoidal hypophysectomy. Journal of Neurosurgery $197134582-594$.

5 Giustina A, Barkan A, Casanueva FF, Cavagnini F, Frohman L, Ho K, Veldhuis J, Wass J, Von Werder K \& Melmed S. Criteria for cure of acromegaly: a consensus statement. Journal of Clinical Endocrinology and Metabolism 200085 526-529.

6 Biermasz NR, van Dulken H \& Roelfsema F. Ten-year follow-up results of transsphenoidal microsurgery in acromegaly. Journal of Clinical Endocrinology and Metabolism 200085 4596-4602.

7 Kreutzer J, Vance ML, Lopes MB \& Laws ER Jr. Surgical management of GH-secreting pituitary adenomas: an outcome study using modern remission criteria. Journal of Clinical Endocrinology and Metabolism $2001864072-4077$.

8 Freda PU, Wardlaw SL \& Post KD. Long-term endocrinological follow-up evaluation in 115 patients who underwent transsphenoidal surgery for acromegaly. Journal of Neurosurgery $1998 \mathbf{8 9}$ $353-358$

9 Holdaway IM \& Rajasoorya C. Epidemiology of acromegaly. Pituitary 19992 29-41.

10 Bates AS, Van't Hoff W, Jones JM \& Clayton RN. An audit of outcome of treatment in acromegaly. Quarterly Journal of Medicine $199386293-299$.

11 Rajasoorya C, Holdaway IM, Wrightson P, Scott DJ \& Ibbertson HK. Determinants of clinical outcome and survival in acromegaly. Clinical Endocrinology 1994 41 95-102.

12 Abosch A, Tyrrell JB, Lamborn KR, Hannegan LT, Applebury CB \& Wilson CB. Transsphenoidal microsurgery for growth hormonesecreting pituitary adenomas: initial outcome and long-term 
results. Journal of Clinical Endocrinology and Metabolism $1998 \mathbf{8 3}$ 3411-3418.

13 Orme SM, McNally RJ, Cartwright RA \& Belchetz PE. Mortality and cancer incidence in acromegaly: a retrospective cohort study. United Kingdom Acromegaly Study Group. Journal of Clinical Endocrinology and Metabolism $1998 \mathbf{8 3} 2730-2734$.

14 Swearingen B, Barker FG 2nd, Katznelson L, Biller BM, Grinspoon S, Klibanski A, Moayeri N, Black PM \& Zervas NT. Long-term mortality after transsphenoidal surgery and adjunctive therapy for acromegaly. Journal of Clinical Endocrinology and Metabolism $1998 \mathbf{8 3} 3419-3426$.

15 Barrande G, Pittino-Lungo M, Coste J, Ponvert D, Bertagna X, Luton JP \& Bertherat J. Hormonal and metabolic effects of radiotherapy in acromegaly: long-term results in 128 patients followed in a single center. Journal of Clinical Endocrinology and Metabolism $2000853779-3785$.

16 Biermasz NR, van Dulken H \& Roelfsema F. Long-term follow-up results of postoperative radiotherapy in 36 patients with acromegaly. Journal of Clinical Endocrinology and Metabolism 200085 2476-2482.

17 Caron P, Morange-Ramos I, Cogne M \& Jaquet P. Three-year follow-up of acromegalic patients treated with intramuscular slow-release lanreotide. Journal of Clinical Endocrinology and Metabolism 199782 18-22.

18 Newman CB, Melmed S, Snyder PJ, Young WF, Boyajy LD, Levy R, Stewart WN, Klibanski A, Molitch ME \& Gagel RF. Safety and efficacy of long-term octreotide therapy of acromegaly: results of a multicenter trial in 103 patients - a clinical research center study. Journal of Clinical Endocrinology and Metabolism $1995 \mathbf{8 0}$ $2768-2775$.

19 Stewart PM, Kane KF, Stewart SE, Lancranjan I \& Sheppard MC. Depot long-acting somatostatin analog (Sandostatin-LAR) is an effective treatment for acromegaly. Journal of Clinical Endocrinology and Metabolism $1995 \mathbf{8 0} 3267-3272$.

20 Trainer PJ, Drake WM, Katznelson L, Freda PU, Herman-Bonert V, van der Lely AJ, Dimaraki EV, Stewart PM, Friend KE, Vance ML, Besser GM, Scarlett JA, Thorner MO, Parkinson C, Klibanski A, Powell JS, Barkan AL, Sheppard MC, Malsonado M, Rose DR, Clemmons DR, Johannsson G, Bengtsson BA, Stavrou S, Kleinberg DL, Cook DM, Phillips LS, Bidlingmaier M, Strasburger CJ, Hackett S, Zib K, Bennett WF \& Davis RJ. Treatment of acromegaly with the growth hormone-receptor antagonist pegvisomant. New England Journal of Medicine $2000 \mathbf{3 4 2}$ $1171-1177$.

21 Baldelli R, Colao A, Razzore P, Jaffrain-Rea ML, Marzullo P, Ciccarelli E, Ferretti E, Ferone D, Gaia D, Camanni F, Lombardi G \& Tamburrano G. Two-year follow-up of acromegalic patients treated with slow release lanreotide $(30 \mathrm{mg})$. Journal of Clinical Endocrinology and Metabolism 200085 4099-4103.

22 Flogstad AK, Halse J, Bakke S, Lancranjan I, Marbach P, Bruns C \& Jervell J. Sandostatin LAR in acromegalic patients: long-term treatment. Journal of Clinical Endocrinology and Metabolism 1997 $8223-28$.

23 Newman CB, Melmed S, George A, Torigian D, Duhaney M, Snyder P, Young W, Klibanski A, Molitch ME, Gagel R, Sheeler L, Cook D, Malarkey W, Jackson I, Vance ML, Barkan A, Frohman L \& Kleinberg DL. Octreotide as primary therapy for acromegaly. Journal of Clinical Endocrinology and Metabolism $1998 \mathbf{8 3}$ 3034-3040.

24 Amato G, Mazziotti G, Rotondi M, Iorio S, Doga M, Sorvillo F, Manganella G, Di Salle F, Giustina A \& Carella C. Long-term effects of lanreotide SR and octreotide LAR on tumour shrinkage and GH hypersecretion in patients with previously untreated acromegaly. Clinical Endocrinology (Oxford) 200256 65-71.

25 Atkin SL, Atkinson AB, Bouloux PM, Hanna F, Harris PE, James RA, McConnell M, Roberts GA, Scanlon MF, Stewart PM, Teasdale E, Turner HE, Wass JA \& Wardlaw JM. Primary medical therapy for acromegaly: an open, prospective, multicenter study of the effects of subcutaneous and intramuscular slow-release octreotide on growth hormone, insulin-like growth factor-I, and tumor size. Journal of Clinical Endocrinology and Metabolism 2002 87 4554-4563.

26 van der Lely AJ, Hutson RK, Trainer PJ, Besser GM, Barkan AL, Katznelson L et al. Long-term treatment of acromegaly with pegvisomant, a growth hormone receptor antagonist. Lancet 2001 358 1754-1759.

27 Sheaves R, Jenkins P, Blackburn P, Huneidi AH, Afshar F, Medbak S, Grossman AB, Besser GM \& Wass JA. Outcome of transsphenoidal surgery for acromegaly using strict criteria for surgical cure. Clinical Endocrinology (Oxford) 199645 407-413.

28 Osman IA, James RA, Chatterjee S, Mathias D \& Kendall-Taylor P. Factors determining the long-term outcome of surgery for acromegaly. Quarterly Journal of Medicine 199487 617-623.

29 Kaltsas GA, Isidori AM, Florakis D, Trainer PJ, Camacho-Hubner C, Afshar F, Sabin I, Jenkins JP, Chew SL, Monson JP, Besser GM \& Grossman AB. Predictors of the outcome of surgical treatment in acromegaly and the value of the mean growth hormone day curve in assessing postoperative disease activity. Journal of Clinical Endocrinology and Metabolism 200186 1645-1652.

30 Ahmed S, Elsheikh M, Stratton IM, Page RC, Adams CB \& Wass JA. Outcome of transphenoidal surgery for acromegaly and its relationship to surgical experience. Clinical Endocrinology (Oxford) $1999 \mathbf{5 0} 561-567$.

31 Lissett CA, Peacey SR, Laing I, Tetlow L, Davis JR \& Shalet SM. The outcome of surgery for acromegaly: the need for a specialist pituitary surgeon for all types of growth hormone (GH) secreting adenoma. Clinical Endocrinology (Oxford) $199849653-657$.

32 Elster AD. Modern imaging of the pituitary. Radiology $1993 \mathbf{1 8 7}$ $1-14$.

33 Marro B, Zouaoui A, Sahel M, Crozat N, Gerber S \& Sourour N. MRI of pituitary adenomas in acromegaly. Neuroradiology 1997 $39394-399$.

34 Cottier JP, Destrieux C, Vinikoff-Sonier C, Jan M \& Herbreteau D. MRI diagnosis of cavernous sinus invasion by pituitary adenomas. Annales d'Endocrinologie (Paris) 200161 269-274.

35 Knosp E, Steiner E, Kitz K \& Matula C. Pituitary adenomas with invasion of the cavernous sinus space: a magnetic resonance imaging classification compared with surgical findings. Neurosurgery $199333610-617$.

36 Rieger A, Rainov NG, Ebel H, Sanchin L, Shibib K, Helfrich C, Hoffmann O \& Burkert W. Factors predicting pituitary adenoma invasiveness in acromegalic patients. Neurosurgical Review 1997 20 182-187.

37 Jenkins D, O’Brien I, Johnson A, Shakespear R, Sheppard MC \& Stewart PM. The Birmingham pituitary database: auditing the outcome of the treatment of acromegaly. Clinical Endocrinology $199543517-522$.

38 Serri O, Somma M, Comtois R, Rasio E, Beauregard H, Jilwan N \& Hardy J. Acromegaly: biochemical assessment of cure after longterm follow-up of transsphenoidal selective adenomectomy. Journal of Clinical Endocrinology and Metabolism 198561 1185-1189.

39 Tindall GT, Oyesiku NM, Watts NB, Clark RV, Christy JH \& Adams DA. Transsphenoidal adenomectomy for growth hormone-secreting pituitary adenomas in acromegaly: outcome analysis and determinants of failure. Journal of Neurosurgery $199378205-215$.

40 Ross DA \& Wilson CB. Results of transsphenoidal microsurgery for growth hormone-secreting pituitary adenoma in a series of 214 patients. Journal of Neurosurgery $1988 \mathbf{6 8} 854-867$.

41 Rieu M, Girard F, Bricaire H \& Binoux M. The importance of insulin-like growth factor (somatomedin) measurements in the diagnosis and surveillance of acromegaly. Journal of Clinical Endocrinology and Metabolism 198255 147-153.

42 Ho KY \& Weissberger AJ. Characterization of 24-hour growth hormone secretion in acromegaly: implications for diagnosis and therapy. Clinical Endocrinology $1994 \mathbf{4 1} 75-83$.

Received 30 December 2003

Accepted 24 February 2004 